\title{
Remediation of Iron Chlorosis by the Addition of Fe-o,o-EDDHA in the Nutrient Solution Applied to Soilless Culture
}

\author{
Miguel Urrestarazu', Juan E. Alvaro, and Soraya Moreno \\ Department of Vegetable Production, University of Almería, La Cañada de \\ San Urbano, Almeria, E-04120 Almería, Spain
}

Gilda Carrasco

Department of Horticulture, Faculty of Agronomic, University of Talca, Talca, Chile

Additional index words. ferric chelates, tomato, green bean, rockwool, perlite

Abstract. The aim of this study was to evaluate the remediation of ferric chlorosis using by iron (Fe)-o,o-EDDHA in fertigation of soilless crops compared with Fe-EDTA (ethylene diamine tetra acetic acid) and its effects on production. Two separate greenhouse experiments were conducted in slab or bag cultures using the tomato (Lycopersicon esculentum Mill. cv. Daniela) and green bean crops (Phaseolus vulgaris L. cv. Maite) in Almería (southeast Spain). The crops were subjected to the following experimental setup: 1) At first phase, all plants were treated with a standard nutrient solution and Fe was supplied as Fe-EDTA. 2) No Fe was supplied in the nutrient solution to bean crops 46 days after transplanting. For tomato plants, this element was eliminated from the nutrient solution since 102 days after transplanting. In this phase, Fe-EDTA was supplied to the control plants (T1). This phase was ended when signs of ferric chlorosis appeared on the leaves. 3) The ferric chlorosis was remediated with either Fe-EDTA (T2) or Fe-o,oEDDHA (T3). The T4 group did not receive any supplements. The total tomato and bean production was improved after the Fe deficiency had been corrected by either EDTA and Fe o,o-EDDHA supplements in the fertigation of these crops. The synthetic Fe o,oEDDHA chelate alleviated $\mathrm{Fe}$ deficiency by increasing the amount of iron in the rhizosphere and its supply to the leaves and petioles. Consequently, the decrease in tomato and bean production resulting from ferric chlorosis could be prevented. As a conclusion, the remediation of ferric chlorosis through fertigation with $\mathrm{Fe} o, o$-EDDHA is as effective as the use of traditional Fe-EDTA.

The use of synthetic iron $(\mathrm{Fe})$ chelates in fertigation is the most common method to alleviate iron deficiency in crops. Several factors that determine the effectiveness of Fe chelates have been described such as the dosage applied and how theses crops are managed (García-Marco et al., 2006). Ethylene diamine tetra acetic acid (EDTA) is among the most commonly used chelating agents in southeastern Spain. However, the most effective chelating agent is actually diamino-di-(ortho-hydroxy phenyl acetic) acid (o,o-EDDHA) (Lucena, 2006), because the final amount of dissolved $\mathrm{Fe}$ obtained from $\mathrm{Fe} o, o$-EDDHA is greater than that from Fe-EDTA (García-Marco et al., 2006), and the dissolved $\mathrm{Fe}$ obtained can be maintained

\footnotetext{
Received for publication 6 Mar. 2008. Accepted for publication 24 Apr. 2008

Part of the work has been supported by project AGL2007-64832/AGR from the Spanish Ministry of Education and Science.

We thank Andy Taylor for his critical discussion reading of the manuscript.

${ }^{1}$ To whom reprint requests should be addressed; e-mailmgavilan@ual.es
}

in solution over a wide range of $\mathrm{pH}$ values (Alcañiz et al., 2004). However, as a result of the high cost, only cash crops are treated with these Fe chelates (Chen and Barak, 1982). Although several researchers have investigated ferric chlorosis and ways to remediate Fe deficiency in crops grown in soil (Marschner et al., 1986; Mengel, 1995) and in soilless crops, few have compared the effects of various synthetic $\mathrm{Fe}$ chelates available in the market (Assimakopoulou, 2006; HernándezApaolaza, 2007; Lucena and Chaney, 2007).

The total area of soilless crops in southeast Spain today is $\approx 5000$ ha, half of which uses rockwool as the growing medium, whereas the other half uses perlite, sand, coir, and other minor soilless systems (Mazuela et al., 2005).

The aim of this study was to evaluate the effectiveness of Fe $o, o$-EDDHA in alleviating ferric chlorosis compared with EDTA in a soilless crop and its effects over production.

\section{Materials and Methods}

Two separate greenhouse experiments were conducted in slab or bag cultures using the tomato (Lycopersicon esculentum Mill. cv. Daniela) and green bean (Phaseolus vulgaris L. cv. Maite) crops in Almería (southeast Spain). Commercially available Grodan ${ }^{\circledR}$ Med. rockwool and Otavi ${ }^{\circledR}$ Ibérica perlite were used in slab and bag cultures for both the tomato and green bean crops. Tomato and green bean seeds were sown on 21 Sept. and transplanted on the 1 and 7 Oct. 2006, respectively. Plant density was two per square meter (six plants per bag or slab). Fertigation was applied independently for each treatment with a localized irrigation system. $\mathrm{pH}$, electric conductivity (EC), individual concentration of each nutrient, time and frequency of nutrient solution application were automatically adjusted depending on the following factors: the developmental stage of plants, the physical and physicalchemical properties of each growing medium, climatic conditions at the real time (particularly irradiation), and the drainage parameters (Salas and Urrestarazu, 2001). Local plant management was performed for each crop (Urrestarazu et al., 2005). Volume, $\mathrm{pH}, \mathrm{EC}$, and chemical analyses of drainage (data not shown, except those for Fe application) were performed weekly. $\mathrm{pH}$ measurements were made using a $\mathrm{pH}$ meter (Crison model 2000, Crison Instruments, Alella, Spain). Except for the addition of Fe chelates used, a standard nutrient solution similar that reported by Sonneveld and Straver (1994) was used.

The crops were subjected to the following experimental setup:

1. At first phase, all plants were treated with a standard nutrient solution and Fe-EDTA was supplied.

2. No Fe was supplied in the nutrient solution to the bean crops $46 \mathrm{~d}$ after sowing. For the tomato plants, this element was eliminated from the nutrient solution $102 \mathrm{~d}$ after transplanting. In this phase, Fe-EDTA was supplied to the control plants (T1). This phase (phase 2) was ended when signs of ferric chlorosis appeared on the leaves (Figs. 1 and 2).

3. Ferric chlorosis was remediated with either Fe-EDTA (treatment 2, T2) or Fe $o, o$-EDDHA [treatment 3 (T3)]. Treatment 4 (T4) group did not receive any supplements. The days after sowing 116 and 46 to tomato and green been were renewed the nutrient solution, respectively.

4. The control plants (T1) were supplied with Fe-EDTA from the beginning to the end of the test.

The Fe concentration in the leaves, drainage, and sap fluids (from leaves without petiole) were determined directly after digestion according to Benton et al. (1996). The measurement was performed by inductively coupled plasma-atomic emission spectroscopy (ICP-AES) using a Spectroflame model ICP-D (SPECTRO Analytical Instruments, Kleve, Germany). All measurements were 


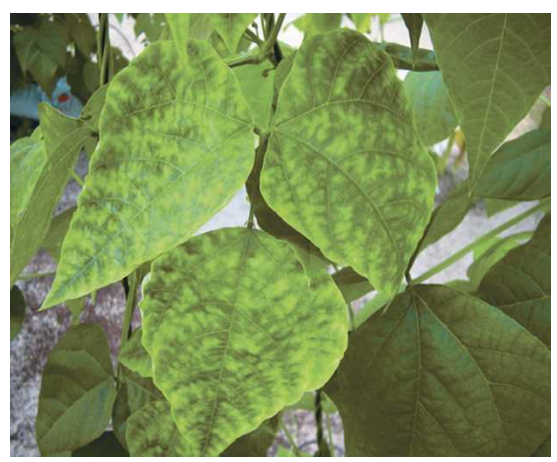

Fig. 1. Iron (Fe) deficiency (central image) and a normal $\mathrm{Fe}$ status in bean plants (right) at the end of phase 2 .

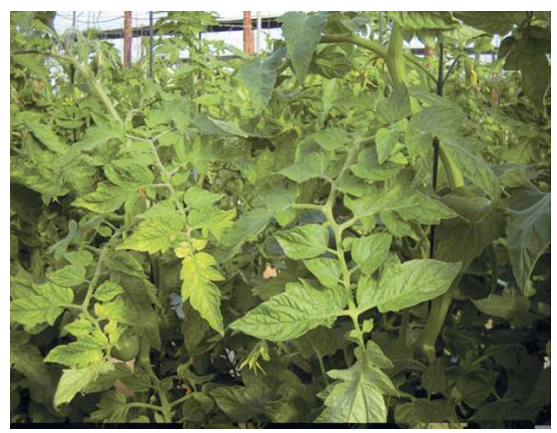

Fig. 2. Iron (Fe) deficiency (left) and a normal Fe status in tomato plants (right) at the end of phase 2 .

performed in triplicate. Each experiment was conducted using the randomized complete block design with four replicates. Twelve plants were assigned to each experimental unit. The least significant difference test was used to compare the significance of the differences in the treatment means obtained. The experimental designs and data analyses were based on the procedure described by Little and Hills (1987). The Stagraphics Plus 4.1 statistical package was used to process the data (Statistical Graphics Corp., 1999).

\section{Results and Discussion}

$\mathrm{Fe}$ is present in drainage fluids of the different treatments for both crops (Table 1). The evaluation of $\mathrm{Fe}$ content in drainage fluids is important because these values can be used as a control parameter of fertigation (Urrestarazu et al., 2005). During the iron deficiency phase (phase 2), the Fe concentration in drainages of $\mathrm{T} 2, \mathrm{~T} 3$, and $\mathrm{T} 4$ was significantly lower than the one of T1 drainage. When $\mathrm{Fe}$ was applied to alleviate ferric chlorosis, the $\mathrm{Fe}$ content detected in the drainage fluids from $\mathrm{T} 4$ (no Fe provided) was much lower than that found in the drainage fluids from both T2 (treatment with Fe-EDTA) and T3 (treatment with $\mathrm{Fe}$ $o, o$-EDDHA). When EDTA and $\mathrm{Fe} o, o$ EDDHA were applied, the Fe content in the drainage fluids reached levels comparable to those found in the drainage fluids from $\mathrm{T} 1$.

The $\mathrm{Fe}$ concentration levels in the leaves (Table 2) are within the range of the reference values known for tomato and green bean crops (Benton et al., 1996; Roorda and Smilde, 1981). During the Fe deficiency period, a significant decrease in the $\mathrm{Fe}$ content in the leaves was observed (Figs. 1 and 2), although the values were still within the normal ranges for both crops.
After the addition of $\mathrm{Fe}$ as a nutrient supplement, the $\mathrm{Fe}$ content in the leaves reached levels similar to those found in the drainage fluids.

The Fe concentration in the sap fluid was similar to that found in the leaves, and no significant differences were found in beans during phase 2 (Table 3 ).

Taken together, the results show that $\mathrm{Fe}$ $o, o$-EDDHA is as effective as the more commonly used Fe-EDTA in alleviating ferric chlorosis. However, because Fe $o, o$-EDDHA

Table 1. The effect of treatments on mean iron $(\mathrm{Fe})$ concentration in drainage in different phases of crops $\left(\mu \mathrm{mol} \cdot \mathrm{L}^{-1}\right)$

\begin{tabular}{|c|c|c|c|c|c|c|c|}
\hline \multirow[b]{2}{*}{ Phase } & \multicolumn{4}{|c|}{ Treatment } & \multicolumn{3}{|c|}{ LSD } \\
\hline & T1 & $\mathrm{T} 2$ & $\mathrm{~T} 3$ & $\mathrm{~T} 4$ & 0.05 & 0.01 & 0.001 \\
\hline \multicolumn{8}{|l|}{ Tomato } \\
\hline \multicolumn{8}{|l|}{ Provoked deficiency } \\
\hline Average values & 43.04 & & $\leftarrow 14.68 \rightarrow$ & & 6.80 & 9.67 & 14.00 \\
\hline Remediated deficiency & 33.81 & 25.01 & 32.08 & 24.10 & 7.39 & & \\
\hline \multicolumn{8}{|l|}{ Green bean } \\
\hline \multicolumn{8}{|l|}{ Provoked deficiency } \\
\hline Average values & 62.79 & & $\leftarrow 40.32 \rightarrow$ & & 19.75 & & \\
\hline Remediated deficiency & 128.12 & 86.31 & 90.75 & 72.92 & 10.05 & & \\
\hline
\end{tabular}

$\mathrm{T} 1=\mathrm{Fe}$ as EDTA all cycle; $\mathrm{T} 2=\mathrm{T} 1$ (phase 1$)+$ provoked Fe deficiency and remediated Fe deficiency with Fe-EDTA; T3 = T2 but remediated Fe deficiency with Fe-o, o-EDDHA; T4 = T2 o T3 without Fe deficiency remediation.

LSD $=$ least significant difference.

Table 2. The effect of treatments on mean leaf concentration iron $(\mathrm{Fe})\left(\mathrm{mmol} \cdot \mathrm{kg}^{-1}\right)$

\begin{tabular}{|c|c|c|c|c|c|c|c|}
\hline \multirow{2}{*}{\multicolumn{2}{|c|}{ Accumulated days }} & \multirow[b]{2}{*}{ Phases } & \multicolumn{4}{|c|}{ Treatment } & \multirow[b]{2}{*}{$\mathrm{LSD}_{0.05}$} \\
\hline & & & $\mathrm{T} 1$ & $\mathrm{~T} 2$ & T3 & T4 & \\
\hline \multirow[t]{5}{*}{ Tomato } & 0 & Sowing & & & & & \\
\hline & 102 & Provoked Fe defici & & & & & \\
\hline & 114 & Average values & 4.38 & & $\leftarrow 2.59-$ & & 1.75 \\
\hline & 116 & Remediated $\mathrm{Fe}$ def & cy & & & & \\
\hline & 155 & & 3.88 & 4.21 & 4.06 & 3.21 & 1.38 \\
\hline \multirow{2}{*}{\multicolumn{4}{|c|}{ Fe normal contents reference values }} & 1.8 & $-7.00^{\mathrm{z}}$ & & \\
\hline & & & & 1.0 & $-5.37^{y}$ & & \\
\hline \multirow[t]{5}{*}{ Green bean } & 0 & Sowing & & & & & \\
\hline & 46 & Provoked Fe defici & & & & & \\
\hline & 81 & Average values & 4.21 & & $\leftarrow 2.97-$ & & 1.24 \\
\hline & 93 & Remediated $\mathrm{Fe}$ def & & & & & \\
\hline & 120 & & 3.18 & 3.28 & 2.07 & 1.05 & 1.02 \\
\hline \multicolumn{4}{|c|}{ Fe normal contents reference values } & \multicolumn{3}{|c|}{$0.90-7.16^{\mathrm{y}}$} & \\
\hline
\end{tabular}

$\mathrm{T} 1=\mathrm{Fe}$ as EDTA all cycle; T2 = T1 (phase 1) + provoked Fe deficiency and remediated Fe deficiency with Fe-EDTA; T3 = T2 but remediated Fe deficiency with Fe- o, o-EDDHA; T4 = T2 o T3 without Fe deficiency remediation.

${ }^{\mathrm{z}}$ Roorda and Smilde (1981).

y'Benton et al., (1996).

LSD $=$ least significant difference.

Table 3. The effect of treatments on sap content iron $(\mathrm{Fe})\left(\mu \mathrm{mol} \cdot \mathrm{kg}^{-1}\right.$ fresh weight $)$

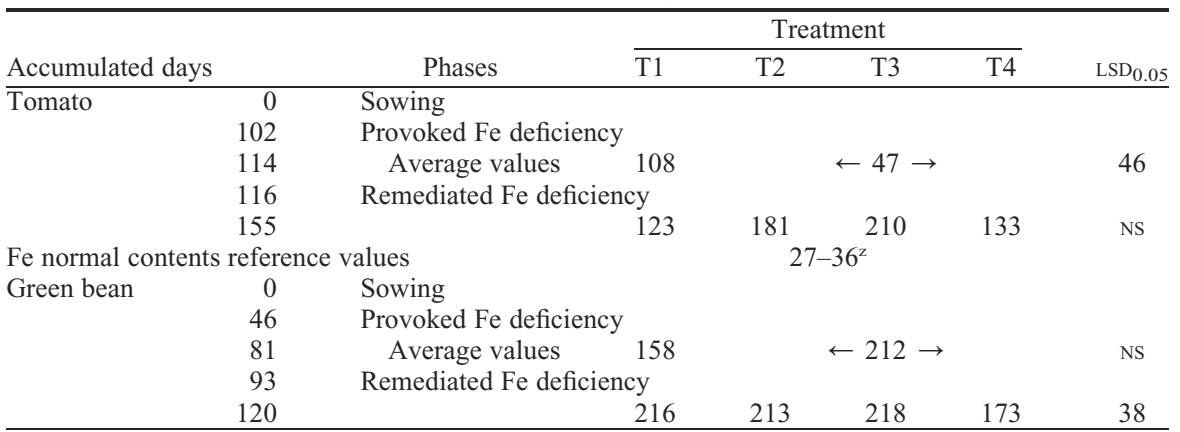

$\mathrm{T} 1=\mathrm{Fe}$ as EDTA all cycle; $\mathrm{T} 2=\mathrm{T} 1$ (phase 1$)+$ provoked Fe deficiency and remediated Fe deficiency with Fe-EDTA; T3 = T2 but remediated Fe deficiency with Fe- o, o-EDDHA; T4 = T2 o T3 without Fe deficiency remediation.

${ }^{\mathrm{z}}$ Roorda and Smilde (1981).

Ns Nonsignificant. 
Table 4. The effect of treatments on crops yield $\left(\mathrm{kg} \cdot \mathrm{m}^{-2}\right)$

\begin{tabular}{|c|c|c|c|}
\hline \multicolumn{4}{|c|}{ Tomato } \\
\hline & Total & Early yield & Green bean \\
\hline T1 & 7.03 & 2.35 & 3.71 \\
\hline $\mathrm{T} 2$ & 6.15 & 1.93 & 2.67 \\
\hline $\mathrm{T} 3$ & 6.25 & 1.99 & 2.81 \\
\hline $\mathrm{T} 4$ & 5.84 & 2.06 & 2.53 \\
\hline $\mathrm{LSD}_{0.05}$ & 0.99 & NS & 1.18 \\
\hline \multicolumn{4}{|c|}{$\begin{array}{l}\mathrm{T} 1=\mathrm{Fe} \text { as EDTA all cycle; } \mathrm{T} 2=\mathrm{T} 1 \text { (phase } 1)+ \\
\text { provoked Fe deficiency and remediated Fe } \\
\text { deficiency with Fe-EDTA; T3 }=\mathrm{T} 2 \text { but } \\
\text { remediated Fe deficiency with Fe-o,o-EDDHA; } \\
\mathrm{T} 4=\mathrm{T} 2 \text { o T3 without Fe deficiency remediation. } \\
\text { Ns Nonsignificant. }\end{array}$} \\
\hline
\end{tabular}

(Alcañiz et al., 2004) remains active for a longer period of time (Lucena, 2006), it is can be considered a more useful supplement in nutrient solution for soilless crops.

The early tomato production shows no significant differences (Table 4). The total tomato and bean production was increased after the remediation of Fe deficiency in the crops by either Fe-EDTA or Fe $o, o$-EDDHA chelate alleviates Fe deficiency by increasing the amount of $\mathrm{Fe}$ in the rhizosphere and its supply to the leaves and petioles. Consequently, the decrease in tomato and bean production resulting from ferric chlorosis can be prevented. As a conclusion, the remediation of ferric chlorosis through fertigation with $\mathrm{Fe} o, o$-EDDHA is as effective as the use of traditional EDTA.

\section{Literature Cited}

Alcañiz, S., M. Cerdán, M. Juárez, J.D. Jordá, D. Bermúdez, and A. Sánchez. 2004. Uptake of $\mathrm{Fe}(o, o$-EDDHA) isomers by strategy I and II plants. Acta Hort. 696:535-542.

Assimakopoulou, A. 2006. Effect of iron supply and nitrogen form on growth, nutritional status and ferric reducing activity of spinach in nutrient solution culture. Sci. Hort. 110:21-29.

Benton, J., B. Wolf, and H.A. Mills. 1996. Plant analysis handbook. Micro-Macro Publishing, Inc., Athens, GA.

Chen, Y. and P. Barak. 1982. Iron nutrition of plants in calcareous soils. Adv. Agron. 35:217240.

García-Marco, S., N. Martínez, F. Yunta, L. HernándezApaolaza, and J.J. Lucena. 2006. Effectiveness or ethylenediamine- $N\left(o\right.$-hydroxyphenylacetic) $-N^{\prime}(p-$ hydroxy-phenylacetic) acid (o,p-EDDHA) to supply iron to plants. Plant Soil 276:31-40.

Hernández-Apaolaza, L. 2007. Aportación de hierro a través del riego incorporando quelatos férricos sintéticos. Vida Rural 246:18-21.

Little, T.M. and F.J. Hills. 1987. Métodos estadísticos para la investigación en la agricultura. Trillas, México.

Lucena, J.J. 2006. Synthetic iron chelates to correct iron deficiency in plants, p. 103-127. In: Barton, L.L. and J. Abadia (Eds.). Iron nutrition in plants and rhizospheric microorganisms. Springer, Berlin.

Lucena, J.L. and R.L. Chaney. 2007. Response of cucumber plants to low doses of different synthetic iron chelates in hydroponics. J. Plant Nutr. 30:795-809.
Marschner, H., H. Römheld, and M. Kissel. 1986. Different strategies in higher plants in mobilization and uptake of iron. J. Plant Nutr. 9:695713.

Mazuela, P., M.C. Salas, and M. Urrestarazu. 2005. Vegetable waste compost as substrate for melon. Commun. Soil Sci. Plant Anal. 36:1557-1572.

Mengel, K. 1995. Ion availability in plant tissuesFerric chlorosis on calcareous soils, p. 389 397. In: Abadia, J. (Ed.). Iron nutrition in soil and plants. Kluwer Academic Publisher, Dordrecht, The Netherlands.

Roorda, J.P.N.L. and K.W. Smilde. 1981. Nutritional disorders in glasshouse tomatoes, cucumbers and lettuce. Centre for Agricultural Publishing and Documentation, Institute for Soil Fertility, Haren (GR.), Glasshouse Crops Research and Experiment Station, Naaldwilk, Wageningen, The Netherlands.

Salas, M.C. and M. Urrestarazu. 2001. Técnicas de fertirrigación en cultivo sin suelo, Manuales de la Universidad de Almería, Servicios de Publicaciones de la Universidad de Almería, Spain.

Sonneveld, C. and N. Straver. 1994. Nutrient solutions for vegetables and flower grow in water or substrates. $10^{\circ}$ ed. Naaldiwijk, The Netherlands: Proefstation voor tuinbouw onder glas te Naaldiwjk.

Statistical Graphics Corp. 1999. STATGRAPHICS Plus for Windows 4.1. Statistical Graphics Crop., Rockville, MD.

Urrestarazu, M., G.A. Martínez, and M.C. Salas. 2005. Almond shell waste: Possible local rockwool substitute in soilless crop culture. Sci. Hort. 103:453-460. 